\title{
ARTÍCULOS
}

\section{CENTROS DE DOCUMENTACIÓN EN TELEVISIÓN Y PRODUCTOS DOCUMENTALES}

\author{
Mabel Giménez-Rayo y Javier Guallar
}

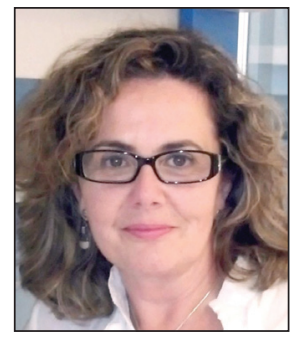

Mabel Giménez-Rayo es doctora en documentación, licenciada en historia antigua, traductora especializada en lengua francesa, magister universitario en biblioteconomía, especialista universitario en criminología y master en dirección de la empresa audiovisual. Desde 1990 trabaja como documentalista audiovisual de televisión y es coordinadora del Departamento de Documentación de Accenture Outsourcing Services para Antena 3 TV. Miembro de la Junta directiva de Sedic como tesorera y coordinadora de la vocalía de formación. Es consultora de la Universitat Oberta de Catalunya en el curso de especialización Documentalista audiovisual y film researcher. http://orcid.org/0000-0001-8638-8875

Accenture Outsourcing Services Fuerteventura, 12 bis. 28703 San Sebastián de los Reyes, Madrid, España mgimenez@spw.es

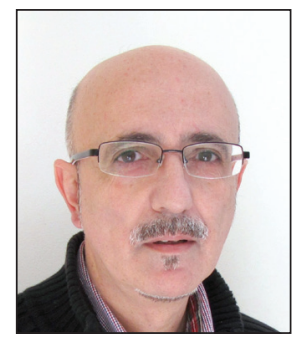

Javier Guallar es profesor en la Facultat de Biblioteconomia i Documentació de la Universitat de Barcelona, Facultat de Comunicació Blanquerna de la Universitat Ramon Llull, Facultat de Comunicació de la Universitat Internacional de Catalunya y colaborador docente en los Estudios de Información y Comunicación de la Universitat Oberta de Catalunya. Anteriormente ha sido documentalista de prensa en varios diarios. Subdirector de la revista El profesional de la información, coordinador del Anuario ThinkEPI y codirector de la colección de libros El profesional de la información (Editorial UOC). Co-autor de El content curator (Editorial UOC, 2013). http://orcid.org/0000-0002-8601-3990

Universitat de Barcelona, Facultat de Biblioteconomia i Documentació Melcior de Palau, 140. 08014 Barcelona, España jguallar@gmail.com

\section{Resumen}

Se presenta una investigación realizada a partir de una encuesta en diez centros de documentación de televisiones españolas. Se analiza en primer lugar la situación actual de las tareas documentales en las cadenas de televisión, tras la digitalización y la realización de algunas de estas funciones por parte de periodistas. En segundo lugar se estudia el nivel de implantación, tipología y problemática de elaboración de productos documentales en los centros de documentación de televisión. Se presenta por primera vez un mapa de la implantación de los productos documentales en las televisiones españolas. Otros resultados son: los periodistas llevan a cabo la selección del material original en 8 de las 10 televisiones estudiadas; el bajo porcentaje de productos documentales que combinan información escrita y audiovisual; y éstos se crean más para uso interno de la redacción que para la audiencia.

\section{Palabras clave}

Documentación audiovisual, Documentación en televisión, Documentación periodística, Centros de documentación, Archivos de televisión, Documentalistas, Periodistas, Formación, Productos documentales.

Title: Television documentation centres and documentary products

\begin{abstract}
The article presents a survey research in 10 documentation centres of Spanish television stations. The authors analyze first the current situation of television documentation tasks after digitization, and the emergence of journalists participation in some of these tasks. Second, we analyze the implementation level, typology and problems of developing documentary products in the documentation centres. For the first time we report a map of the implementation of documentary products in the Spanish television stations. Other results found were: journalists perform the selection of the original materials in 8 of the 10 television stations studied; few documentary products combine text and audiovisual information, and these are usually created for internal use in the news room and not for the audience.
\end{abstract}




\section{Keywords}

Audiovisual documentation, Documentation in television, Journalistic documentation, News librarianship, Television archives, Documentation centres, Documentalists, Information scientists, News librarians, Journalists, Training, Documentation products.

Giménez-Rayo, Mabel; Guallar, Javier (2014). "Centros de documentación en televisión y productos documentales". El profesional de la información, enero-febrero, v. 23, n. 1, pp. 13-25.

http://dx.doi.org/10.3145/epi.2014.ene.02

\section{Introducción}

\subsection{Antecedentes}

La documentación audiovisual en televisión ha sido objeto de numerosos estudios académicos y profesionales, tanto de alcance genérico (entre los más recientes, los libros de Caridad-Sebastián et al., 2011 y de Caldera-Serrano y Arranz-Escacha, 2012), como especializados en diferentes temas, entre los que cabe destacar los trabajos sobre centros de documentación concretos (De-Bustos-Pérez-de-Salcedo, 2007; Alfonso-Noguerón, 2009; Estrada-Nora-González; Patallo-Fernández; Pastor-Blanco, 2009; Aguilar-Gutiérrez; López-De-Solís, 2010; Conesa-Santamaría, 2012) y los que analizan la situación y las tendencias de la documentación en televisión a raíz de la digitalización (Hidalgo-Goyanes, 2005; Agirreazaldegi-Berriozabal, 2007; López-de-Quintana, 2007; Giménez-Rayo, 2012).

Por otra parte, enlazando con el análisis de la evolución de la documentación en televisión, algunos estudios abordan la oportunidad que representa para los documentalistas de los medios la realización de tareas diferentes a las tradicionales, o bien, la necesidad de dar nuevos enfoques a tareas ya existentes. En este planteamiento se sitúan los trabajos de Rubio-Lacoba (2007; 2011), Guallar (2011a, 2011b y 2013), y Guallar; Abadal; Codina (2012), que analizan los productos documentales en los cibermedios y, en especial, en la prensa digital. Guallar (2011a, p. 76) enfatiza la oportunidad que representa para los documentalistas la creación o co-creación de contenidos dirigidos al usuario final. Para el ámbito televisivo, Giménez-Rayo (2012, pp. 92-95) ha propuesto tres actividades que los documentalistas de televisión deben potenciar en el futuro: control del material audiovisual en los sistemas digitales, elaboración de productos documentales, y formación, un aspecto al que también se han referido Caldera-Serrano y Arranz-Escacha (2012).

\subsection{Objetivos y metodología}

Este trabajo persigue un doble objetivo:

- actualizar el análisis de la situación de las tareas documentales en los centros de documentación de las televisiones en España, tanto en lo que se refiere a las funciones documentales consideradas "clásicas" como a las que han sido propuestas más recientemente en la bibliografía, como la formación y la elaboración de productos documentales;

- estudiar las características de uso de los productos documentales en los servicios de documentación, estableciendo sus tipos, grado de implantación y problemas de su realización.

La evolución de las tareas documentales en los departamentos de documentación, en un contexto marcado por cambios y transformaciones, como es patente en la bibliografía antes mencionada, justifica la realización de estudios periódicos, el primero de los objetivos de este trabajo. El segundo objetivo se justifica en la ausencia en la bibliografía especializada de estudios sobre este tipo de productos y especialmente sobre su elaboración.

La metodología seguida es la investigación por encuesta, método de investigación que tiene una amplia tradición en disciplinas instrumentales de ciencias sociales, como es el caso de Información y Documentación.

Se elaboró un cuestionario formado por preguntas estructuradas y no estructuradas en torno a los dos objetivos antes señalados, que se envió a 13 centros de documentación de televisiones españolas, públicas y privadas, estatales y autonómicas y una local. De los 13 centros, respondieron los 10 siguientes $^{1}$ :

\author{
- Antena 3 TV \\ - Barcelona Televisió (BTV) \\ - Compañía de Radio/Televisión de Galicia (CRTVG) \\ - Euskal Irrati Telebista (EITB) \\ - La sexta \\ - Radiotelevisión del Principado de Asturias (RTPA) \\ - Radiotelevisió Valenciana (RTVV) \\ - Telecinco \\ - Telemadrid \\ - Televisió de Catalunya (TVC)
}

La lista de productos documentales que forma parte del cuestionario enviado se confeccionó a partir de GiménezRayo (2012, pp. 94-95), Guallar (2011a, p. 13; 2011b, p. 60) y Rubio-Lacoba (2011, p. 112). El cuestionario se envió a los centros en junio de 2013 y las respuestas se recibieron entre los meses de julio y septiembre del mismo año.

\section{Resultados}

\subsection{Personal}

La plantilla media de los servicios de documentación de las televisiones en España a septiembre de 2013 oscila en torno a los 16-20 documentalistas (la mitad de los centros estudiados se encuentra en esa situación), como se muestra en la tabla $1^{2}$. En los extremos se encuentran por una parte 3 centros con una plantilla de 10 o menos documentalistas (de
Tabla 1. Plantilla de los centros de documentación

\begin{tabular}{|l|c|}
\hline \multicolumn{1}{|c|}{ Cadena } & Plantilla \\
\hline TVC & 38 \\
\hline Antena 3 TV & 32 \\
\hline CRTVG & 19 \\
\hline Telemadrid & 17 \\
\hline La sexta & 16 \\
\hline RTVV & 16 \\
\hline Telecinco & 16 \\
\hline EITB & 10 \\
\hline BTV & 6 \\
\hline RTPA & 5 \\
\hline
\end{tabular}


Tabla 2. Labores documentales realizadas por los periodistas

\begin{tabular}{|c|c|c|c|c|c|}
\hline & $\begin{array}{c}\text { Selección material } \\
\text { original }\end{array}$ & $\begin{array}{l}\text { Búsqueda de información } \\
\text { escrita en bases propias }\end{array}$ & $\begin{array}{l}\text { Búsqueda de informa- } \\
\text { ción escrita en internet }\end{array}$ & $\begin{array}{c}\text { Búsqueda de material } \\
\text { audiovisual en bases } \\
\text { propias }\end{array}$ & $\begin{array}{c}\text { Búsqueda de material } \\
\text { audiovisual en } \\
\text { internet }\end{array}$ \\
\hline Antena 3 TV & Sí & No & Sí & Sí & Sí \\
\hline BTV & Sí & No & Sí & Sí & Sí \\
\hline CRTVG & No & No & Sí & Sí & Sí \\
\hline EITB & Sí & Sí & Sí & Sí & No \\
\hline La sexta & Sí & No & Sí & Sí & Sí \\
\hline RTPA & Sí & Sí & Sí & Sí & Sí \\
\hline$R T V V$ & Sí & No & Sí & Sí & Sí \\
\hline Telecinco & Sí & No & Sí & No & Sí \\
\hline Telemadrid & No & No & Sí & No & Sí \\
\hline TVC & $\overline{\text { Sí }}$ & $\overline{\text { Sí }}$ & Sí & Sí & Sí \\
\hline
\end{tabular}

Tabla 3. Labores documentales realizadas por los documentalistas

\begin{tabular}{|c|c|c|c|c|c|c|}
\hline & $\begin{array}{l}\text { Análisis de la } \\
\text { emisión }\end{array}$ & $\begin{array}{c}\text { Selección del } \\
\text { material original }\end{array}$ & $\begin{array}{l}\text { Análisis del ma- } \\
\text { terial original }\end{array}$ & $\begin{array}{l}\text { Búsqueda de in- } \\
\text { formación escrita }\end{array}$ & $\begin{array}{l}\text { Búsqueda de ma- } \\
\text { terial audiovisual }\end{array}$ & Otras \\
\hline Antena 3 TV & Sí & Sí & Sí & Sí & Sí & \\
\hline BTV & No & Sí & Sí & Sí & Sí & \\
\hline CRTVG & Sí & Sí & No & Sí & Sí & \\
\hline EITB & Sí & $\mathrm{No}^{3}$ & Sí & Sí & Sí & \\
\hline La sexta & Sí & Sí & Sí & No & Sí & $\begin{array}{l}\text { Gestión de contenidos en los } \\
\text { sistemas digitales }\end{array}$ \\
\hline RTPA & Sí & Sí & Sí & Sí & Sí & \\
\hline$R T V V$ & Sí & Sí & Sí & Sí & Sí & Búsqueda de música \\
\hline Telecinco & Sí & Sí & Sí & Sí & Sí & \\
\hline Telemadrid & Sí & Sí & Sí & Sí & Sí & $\begin{array}{l}\text {-Gestión del videoservidor; } \\
\text {-Gestión de altas de títulos y } \\
\text { derechos; } \\
\text {-Control de la emisión; } \\
\text {-Venta de imágenes de archivo. }\end{array}$ \\
\hline TVC & Sí & Sí & Sí & Sí & Sí & Sí, sin especificar. \\
\hline
\end{tabular}

los que uno pertenece a una televisión local, BTV), y por otra 2 departamentos que sobrepasan los 30 empleados: TVC con 38 y Antena $3 T V$ con 32. Ambos son los servicios de documentación de mayores dimensiones de la muestra estudiada y son, previsiblemente junto a TVE, de la que no poseemos datos, los mayores de España. Estas cifras hay que situarlas en la coyuntura actual de recortes de plantilla y EREs, como los que han vivido en los últimos meses Telemadrid y RTVV.

\subsection{Tareas documentales realizadas por periodistas}

Se preguntó por la realización por periodistas de funciones llevadas a cabo tradicionalmente por documentalistas, tales como la selección de material y la búsqueda de información escrita y audiovisual en fuentes internas y externas.

Los resultados (tabla 2) indican la realización habitual de algunas de estas funciones por los redactores, fundamentalmente la búsqueda de información escrita en internet (en todas las televisiones lo hacen), así como la de material audiovisual en internet (en 9 de los 10 centros) y en bases de datos propias (en 8).

Es significativo asimismo que los periodistas lleven a cabo la selección del material original en 8 de las 10 televisiones

\begin{tabular}{|c|c|c|}
\hline & $\begin{array}{c}\text { Búsqueda en } \\
\text { internet }\end{array}$ & $\begin{array}{c}\text { Búsqueda en } \\
\text { bases de datos } \\
\text { propias }\end{array}$ \\
\hline Antena $3 \mathrm{TV}$ & No & Sí \\
\hline BTV & No & Sí \\
\hline EITB & No & No \\
\hline La sexta & No & Sí \\
\hline Telecinco & No & Sí \\
\hline Telemadrid & No & Sí \\
\hline TVC & No & Sí \\
\hline RTPA & Sí & Sí \\
\hline CRTVG & Sí & Sí \\
\hline RTVV & No & Sí \\
\hline
\end{tabular}

de la muestra, si bien hay que matizar que esta selección no tiene en todas las cadenas la misma trascendencia para los departamentos de documentación, ya que en algunas tiene sólo un carácter orientativo y no sustituye a la realizada por los documentalistas, como reflejan las respuestas de RTVV y La sexta. En el primer caso, la selección por periodistas no está sistematizada y "aunque se ha incrementado, la reali- 
Tabla 5. Tipos de productos documentales en televisión

\begin{tabular}{|c|c|c|c|c|c|c|c|c|c|c|c|c|c|}
\hline & $\begin{array}{l}\text { Bio- } \\
\text { gra- } \\
\text { fías }\end{array}$ & $\begin{array}{l}\text { Cronolo- } \\
\text { gías de } \\
\text { aconteci- } \\
\text { mientos } \\
\text { en curso }\end{array}$ & $\begin{array}{c}\text { Dossiers } \\
\text { temáti- } \\
\text { cos }\end{array}$ & $\begin{array}{l}\text { Efe- } \\
\text { méri- } \\
\text { des }\end{array}$ & $\begin{array}{c}\text { Fichas } \\
\text { de } \\
\text { orga- } \\
\text { nismos }\end{array}$ & $\begin{array}{l}\text { Fichas } \\
\text { de } \\
\text { países }\end{array}$ & $\begin{array}{c}\text { Guía de } \\
\text { recur- } \\
\text { sos en } \\
\text { inter- } \\
\text { net }\end{array}$ & $\begin{array}{l}\text { Libre- } \\
\text { ría de } \\
\text { recur- } \\
\text { sos }\end{array}$ & $\begin{array}{c}\text { Piezas } \\
\text { con ma- } \\
\text { terial de } \\
\text { archivo } \\
\text { para la } \\
\text { web }\end{array}$ & $\begin{array}{l}\text { Previ- } \\
\text { siones }\end{array}$ & $\begin{array}{c}\text { Reporta- } \\
\text { jes con } \\
\text { material } \\
\text { de archi- } \\
\text { vo }\end{array}$ & $\begin{array}{l}\text { Resú- } \\
\text { menes } \\
\text { del } \\
\text { año }\end{array}$ & Total \\
\hline TVC & Sí & Sí & Sí & Sí & Sí & No & Sí & Sí & Sí & Sí & Sí & Sí & 11 \\
\hline EITB & Sí & No & Sí & Sí & No & No & No & No & No & Sí & Sí & Sí & 6 \\
\hline Antena $3 \mathrm{TV}$ & Sí & Sí & Sí & No & No & No & No & Sí & No & No & No & Sí & 5 \\
\hline RTVV & Sí & Sí & Sí & No & No & No & No & No & Sí & No & Sí & No & 5 \\
\hline Telecinco & Sí & Sí & Sí & No & No & No & No & No & No & No & No & Sí & 4 \\
\hline BTV & No & No & No & Sí & Sí & No & Sí & No & No & No & No & No & 3 \\
\hline Telemadrid & Sí & No & Sí & No & No & No & No & No & No & No & Sí & No & 3 \\
\hline RTPA & Sí & No & No & No & No & No & No & No & No & No & Sí & Sí & 3 \\
\hline CRTVG & Sí & No & No & No & No & No & No & No & Sí & No & No & No & 2 \\
\hline La sexta & No & No & No & No & No & No & No & No & No & No & No & No & 0 \\
\hline Total & 8 & 4 & 6 & 3 & 2 & 0 & 2 & 2 & 3 & 2 & 5 & 5 & \\
\hline
\end{tabular}

Tabla 6. Fuentes para la elaboración de productos documentales

\begin{tabular}{|l|c|c|l|}
\hline & $\begin{array}{c}\text { ¿Elabora el centro todos } \\
\text { los productos que ofrece? }\end{array}$ & $\begin{array}{c}\text { iRecurren a compañías externas para } \\
\text { elaborar estos productos documentales? } \\
\text { ¿A cuáles? }\end{array}$ & $\begin{array}{c}\text { ¿Utilizan productos elaborados por otros medios } \\
\text { como fuentes o para crear los suyos? ¿Cuáles? }\end{array}$ \\
\hline Antena 3 TV & Sí & Efedata & Efedata \\
\hline BTV & Sí & No & No \\
\hline CRTVG & Sí & No & $\begin{array}{l}\text { Efedata; y los servicios pdf de prensa diaria de Orbyt } \\
\text { y Kiosko y Más }\end{array}$ \\
\hline EITB & & No & Noticias de periódicos y revistas \\
\hline La sexta & Sí & No & No \\
\hline RTPA & Sí & No & MyNews e internet \\
\hline RTVV & Sí & Efedata & Anuarios de agencias e internet \\
\hline Telecinco & Sí & No & No \\
\hline Telemadrid & Sí sin especificar \\
\hline TVC & & &
\end{tabular}

Tabla 7. Tipo de información contenida en los productos documentales de televisión

\begin{tabular}{|c|c|}
\hline & $\begin{array}{c}\text { ¿Qué información contienen sus } \\
\text { productos? }\end{array}$ \\
\hline Antena 3 TV & Escrita/audiovisual \\
\hline BTV & Ambas \\
\hline CRTVG & Escrita/audiovisual/ambas \\
\hline EITB & Escrita \\
\hline \multicolumn{2}{|l|}{ La sexta } \\
\hline RTPA & Audiovisual \\
\hline$R T V V$ & Escrita/ambas \\
\hline Telecinco & Ambas \\
\hline \multicolumn{2}{|l|}{ Telemadrid } \\
\hline TVC & Ambas \\
\hline
\end{tabular}

zan de manera esporádica; se trata más de personas concretas que de un sistema que se aplique a la redacción". En La sexta, indican que "la selección del material original no es exclusiva del periodista, pero se usa como guía".
Por último, la única de las tareas típicamente documentales que no realizan de una manera mayoritaria los periodistas de los centros consultados es la búsqueda de información escrita en las bases de datos propias: tan sólo lo hacen en 3 de las 10 televisiones consultadas.

\subsection{Tareas documentales realizadas por el centro de documentación}

La pregunta acerca de las tareas documentales clásicas de un servicio de documentación ofrece resultados esperables (tabla 3). Con pocos matices y excepciones, los centros consultados responden afirmativamente a la realización de estas funciones habituales de la documentación audiovisual en televisión: selección del material original, análisis de la emisión y del material original y recuperación de la información tanto escrita como audiovisual. Es interesante resaltar que a la petición a los centros de que señalaran en su caso otras tareas, algunos mencionan la gestión de los contenidos audiovisuales en los sistemas digitales, una labor que en la mayoría de las ocasiones es desempeñada por informáticos y no por documentalistas. 
Tabla 8. Objetivos de la elaboración de productos documentales en televisión

\begin{tabular}{|l|l|}
\hline Antena 3 TV & Ofrecer un mejor servicio basado en la anticipación \\
\hline BTV & Facilitar las tareas de catalogación \\
\hline CRTVG & $\begin{array}{l}\text { Doble uso: servicio público (piezas para el futuro archivo online histórico de CRTVG) e información para el trabajo diario de los } \\
\text { documentalistas que por supuesto también revierte en los usuarios (redactores, realizadores, guionistas, etc.) del medio. }\end{array}$ \\
\hline EITB & Satisfacer las necesidades de los usuarios \\
\hline La sexta & \\
\hline RTPA & Satisfacer las necesidades de los redactores y que tengan un acceso a la información más rápido y eficaz \\
\hline RTVV & Completar información que no posee el archivo \\
\hline Telecinco & Facilitar la labor a los redactores \\
\hline Telemadrid & \\
\hline TVC & Difusión del material propio y dar respuesta a todas las consultas de nuestros usuarios \\
\hline
\end{tabular}

Tabla 9: Medio de difusión de los productos documentales en televisión

\begin{tabular}{|l|l|}
\hline Antena 3 TV & Medios internos \\
\hline BTV & Sólo para uso del departamento de documentación \\
\hline CRTVG & Web corporativa e intranet \\
\hline EITB & \\
\hline La sexta & \\
\hline RTPA & Sistema interno de gestión documental de la empresa \\
\hline RTVV & Información a los responsables de Informativos \\
\hline Telecinco & Comunicación a la dirección de Informativos \\
\hline Telemadrid & \\
\hline TVC & $\begin{array}{l}\text { Intranet, correo electrónico, FTP, papel, discos duros } \\
\text { externos, DVD }\end{array}$ \\
\hline
\end{tabular}

\subsection{Formación de usuarios}

Todos los departamentos consultados menos uno llevan a cabo acciones de formación de usuarios (tabla 4). Esto, que es un dato positivo, se debe matizar ya que la formación se limita en la mayoría de los casos al manejo de las bases de datos propias y de las herramientas relacionadas con el servicio de documentación. Sólo dos centros ofrecen otro tipo de formación, como técnicas de búsqueda en internet.

\subsection{Implantación de los productos documentales en televisión}

Todos los departamentos menos uno elaboran algún producto documental. La tabla 5 muestra el nivel de implantación en las televisiones de los productos por los que se les preguntó. Hay que señalar que los centros no han añadido otros diferentes a los que se indicaban en el cuestionario, por lo que esta relación describe la situación actual de elaboración de estos productos en las televisiones españolas.

La mayoría de servicios de documentación elabora una media de 4 o 5 productos documentales. Sólo una cadena no los realiza: La sexta, porque considera que "es difícil ajustarlos a las redacciones a las que da servicio". Por otra parte, RTPA, aunque en la tabla se indique que realizan tres de ellos, hay que aclarar que no los elabora directamente, sino que facilita su realización a los redactores a través de la inclusión de metadatos específicos (como "biografía" o "resumen del año"), ya que en esta cadena son los redactores quienes buscan el material y no los documentalistas. En el otro extremo, se encuentra el departamento que elabora más productos, que es también el mayor en dimensiones de la muestra, TVC, con 11. Le siguen a cierta distancia EITB (6) y Antena 3 TV y RTVV (5).

Los productos documentales más generalizados en los servicios de documentación son las biografías (8 centros), dossiers temáticos (6), reportajes con material de archivo (5), resúmenes anuales (5) y cronologías de acontecimientos en curso (4). El resto de productos alcanzan valores bajos (están presentes en 3, 2 o 1 centro). Entre estos últimos se encuentran las piezas para la web con material de archivo (3). El único producto documental de la tipología presentada que no se realiza en ninguno de los centros estudiados son las fichas de países.

Los productos documentales más generalizados son biografías, dossiers temáticos, reportajes con material de archivo, resúmenes anuales y cronologías de acontecimientos en curso

\subsection{Características de la realización de productos do- cumentales}

Todos los departamentos encuestados elaboran los productos documentales que ofrecen, aunque algunos también recurren a los realizados por otros medios, normalmente de la prensa impresa y digital (tabla 6).

A pesar de la digitalización, todavía son pocos los que combinan en un mismo producto información escrita con audiovisual, como el ejemplo emblemático de la agenda de InaMédiaPro (ver más adelante la figura 4). Por este motivo, en la tabla 7 se muestra la información recogida sobre el tipo de contenido: "escrita", cuando sólo contienen información escrita; "audiovisual", sólo imagen, o "ambas", una combinación de las dos.

Las respuestas sobre los objetivos que se persiguen con la elaboración de los productos documentales (tabla 8) indican que estos se crean fundamentalmente para uso interno de la redacción de la cadena y no para consumo de la audiencia, por lo que los canales habilitados para su difusión suelen ser los internos (tabla 9). La excepción más clara a esta norma general es el caso de CRTVG, que, tanto en las respuestas a los objetivos como a los canales de difusión, 
Tabla 10. Problemática de la elaboración de productos documentales en televisión

\begin{tabular}{|c|c|c|}
\hline & ¿Por qué no elaboran éstos o más productos? & $\begin{array}{l}\text { ¿Cuáles son los principales problemas que plantea la } \\
\text { elaboración de estos productos documentales? }\end{array}$ \\
\hline Antena 3 TV & $\begin{array}{l}\text {-No se ha planteado la necesidad (Guía de recursos de internet, Fi- } \\
\text { chas de organismos, Fichas de países) } \\
\text {-Porque se manejan fuentes externas (Efemérides) } \\
\text {-Porque los elaboran los propios redactores. } \\
\text {-La elaboración de reportajes se planteó en un momento pero no } \\
\text { se llegó a hacer por diferentes motivos }\end{array}$ & $\begin{array}{l}\text {-Conocer las necesidades } \\
\text {-La disponibilidad de recursos humanos para las tareas de } \\
\text { actualización }\end{array}$ \\
\hline BTV & & -Actualización \\
\hline CRTVG & & $\begin{array}{l}\text {-Falta de recursos (quitan tiempo de otros trabajos más } \\
\text { necesarios) } \\
\text {-Tiempo que requieren }\end{array}$ \\
\hline \multicolumn{3}{|l|}{ EITB } \\
\hline La sexta & $\begin{array}{l}\text {-Por la línea editorial } \\
\text {-Suponen mucho tiempo de producción } \\
\text {-La usabilidad: dificultad en ajustarlos a todas las redacciones a las } \\
\text { que se atiende }\end{array}$ & \\
\hline RTPA & $\begin{array}{l}\text {-Debido a los recortes presupuestarios sufridos en el servicio de } \\
\text { documentación, los recursos humanos y tecnológicos son muy li- } \\
\text { mitados por lo que se hace inviable la elaboración de más produc- } \\
\text { tos documentales que los señalados. }\end{array}$ & -Falta de personal \\
\hline RTVV & $\begin{array}{l}\text {-Se realizan a demanda, aunque en ocasiones se elaboran con an- } \\
\text { ticipación } \\
\text {-Falta de recursos }\end{array}$ & $\begin{array}{l}\text {-Coste económico } \\
\text {-Esfuerzo en actualización (conocimiento de otras herra- } \\
\text { mientas) }\end{array}$ \\
\hline Telecinco & $\begin{array}{l}\text {-Sólo se realizan a petición de la Dirección de informativos o de los } \\
\text { Jefes de sección }\end{array}$ & $\begin{array}{l}\text {-Falta de tiempo } \\
\text {-Escasez de personal }\end{array}$ \\
\hline Telemadrid & $\begin{array}{l}\text {-Se realizan a demanda de redacción o realización, el centro de } \\
\text { documentación no los elabora a priori por falta de personal y de } \\
\text { tiempo }\end{array}$ & \\
\hline TVC & & $\begin{array}{l}\text {-Selección } \\
\text {-Alto coste } \\
\text {-Disponibilidad de recursos propios }\end{array}$ \\
\hline
\end{tabular}

deja clara la doble función de uso interno y externo.

En general, estos productos son bien aceptados por los redactores. Sin embargo, su realización presenta en la actualidad importantes obstáculos, como se recoge en las respuestas de la tabla 10 sobre los motivos por los que el centro no elabora más productos y los principales problemas que conlleva su elaboración.

\subsection{Relación de productos documentales y ejemplos}

A partir de las respuestas obtenidas sobre su elaboración en la actualidad (tabla 5) así como de los ejemplos facilitados por los centros, se ha establecido la siguiente relación de productos documentales en televisión junto a algunas muestras de buenas prácticas. Para cada producto se pre-
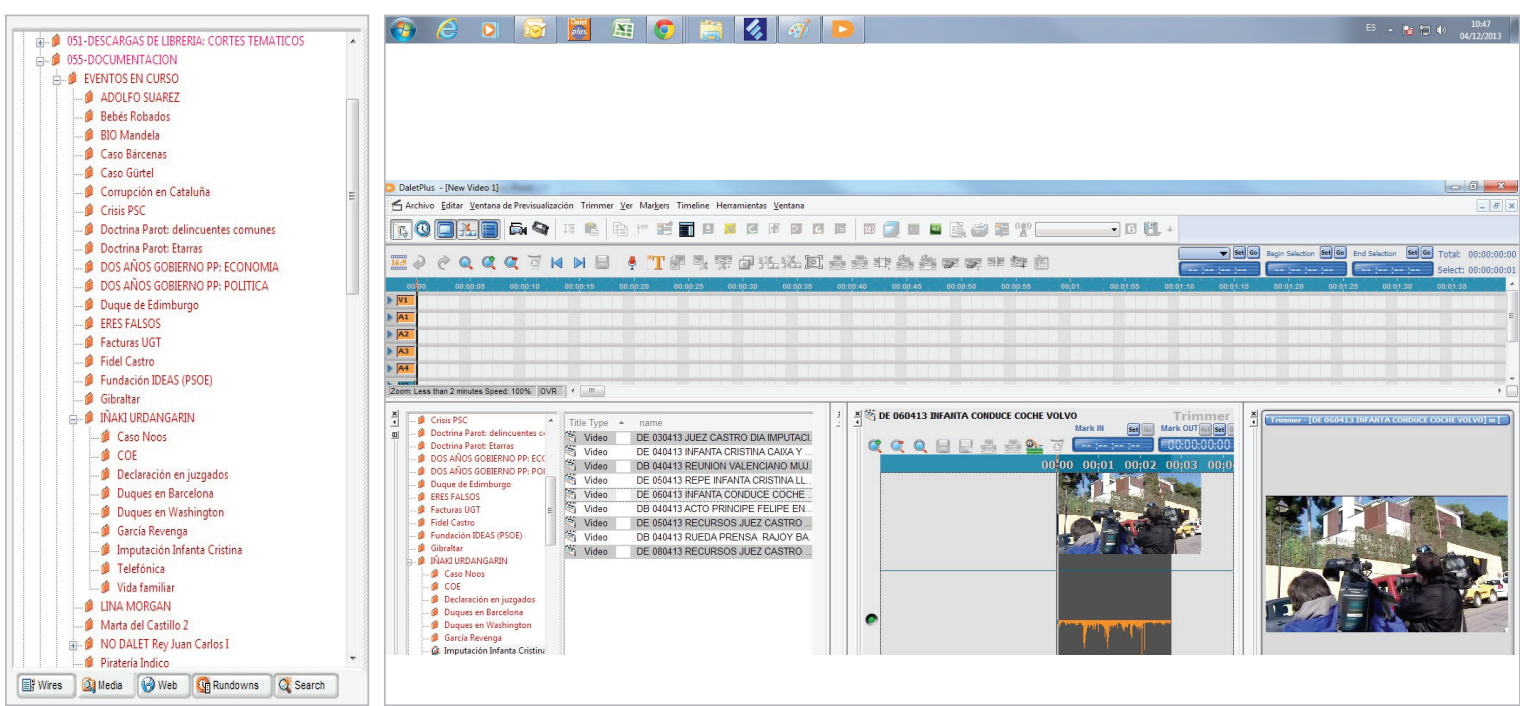

Figura 1. Eventos en curso de Antena 3 TV 
senta una breve descripción, el tipo de información que ofrece (textual, audiovisual o ambas), el número de centros que lo realizan y un ejemplo.

\section{Biografías}

Se trata de documentos, habitualmente en orden cronológico, de los principales acontecimientos de la vida de un personaje público. Muestran información sobre los momentos clave del personaje y material audiovisual relativo a ellos. Todas las cadenas encuestadas las realizan, con la excepción de BTV y de La sexta (que no realiza productos documentales). Son muy útiles para noticias de última hora como necrológicas, nombramientos, concesión de premios, etc.

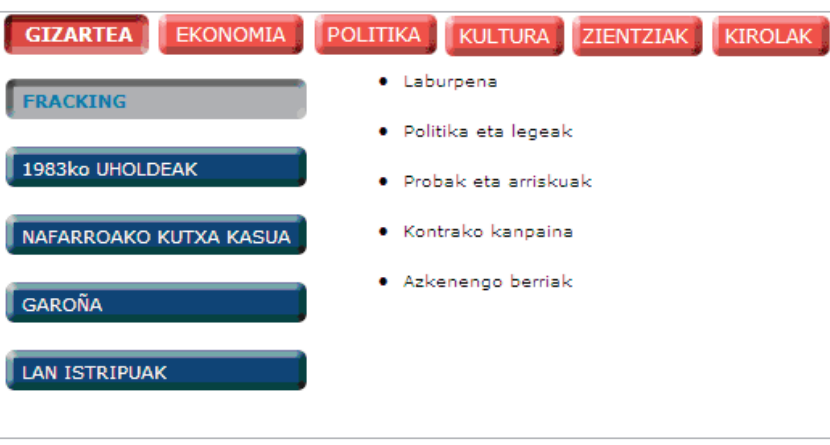

Figura 2. Dossiers temáticos de EITB

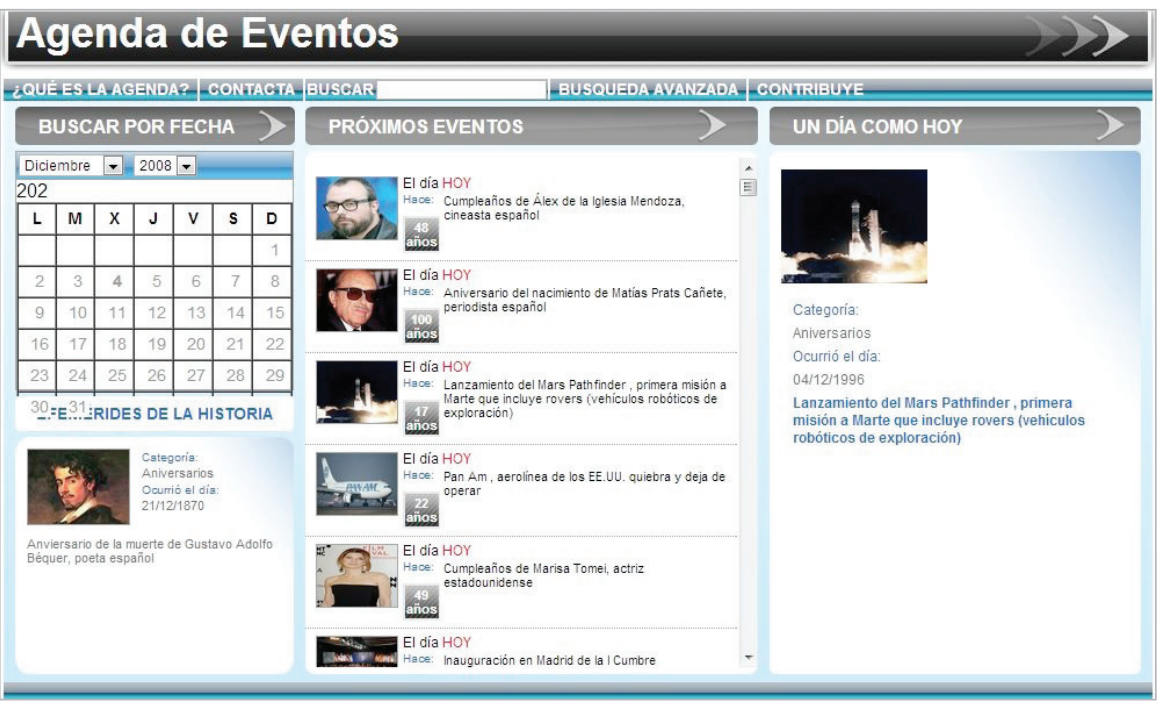

Figura 3. Agenda de eventos de Antena 3 TV

\section{Cronologías de acontecimientos en curso}

Relación de los principales hitos en acontecimientos de largo desarrollo. Por ejemplo, en 2013: conflictos internacionales como la guerra civil en Siria, o acontecimientos polémicos que se dilatan en el tiempo, como el asesinato de Asunta Basterra, el caso Bárcenas, los EREs en Andalucía, etc. Ofrecen información sobre los hechos y material audiovisual relacionado con ellos. De las televisiones encuestadas, cuatro realizan este producto (Antena $3 T V, R T V V$, Telecinco y TVC). Se debe destacar la opción adoptada por Antena $3 T V$, que pone a disposición de los usuarios de la redacción en acceso online el material relacionado con estos acontecimientos en curso, lo que evita repetir búsquedas constantemente durante el período de vigencia de la noticia. El material audiovisual (no incluye información escrita) se organiza en el sistema de edición en subcarpetas dentro de una carpeta genérica llamada "Eventos en curso" (figura 1), de tal manera que el redactor tiene el material disponible mientras monta la pieza.

\section{Dossiers temáticos}

Relación de acontecimientos que se repiten periódicamente, como competiciones deportivas, fichajes deportivos del año, campañas electorales, etc. Incluyen información sobre los hechos y material audiovisual relativo a ellos. Seis cadenas de las encuestadas (Antena 3 TV, EITB -figura 2-, RTVV, Telecinco, Telemadrid y TVC) los realizan aunque, como en los casos anteriores, no combinan la información escrita con la audiovisual. EITB elabora además dossiers semanales (Proposamenak), personalizados según el perfil del usuario, sólo con información escrita.

\section{Efemérides}

Relación cronológica de hechos importantes del pasado que se recuerdan con motivo de su aniversario. Incluyen información escrita del acontecimiento y principal material audiovisual relacionado. Tres cadenas (BTV, EITB y TVC) los realizan, aunque sólo aportan información escrita. Antena 3 TV inició en 2008 un producto similar ("La agenda de eventos", figura 3), que combinaba efemérides con previsiones, sólo con información escrita, aunque entre sus objetivos iniciales estaba incorporar el material audiovisual (López-de-Quintana, 2008, p. 16), pero dejó de elaborarlo. Como ejemplo de lo que puede ser un producto de este tipo, se puede citar la Agenda de InaMédiaPro 4 (figura 4), que sí combina los dos tipos de información (escrita y audiovisual), aunque se debe matizar que el INA (Institut National de l'Audiovisuel) no es propiamente un centro de documentación de televisión sino una empresa pública encargada de salvaguardar el patrimonio audiovisual francés.

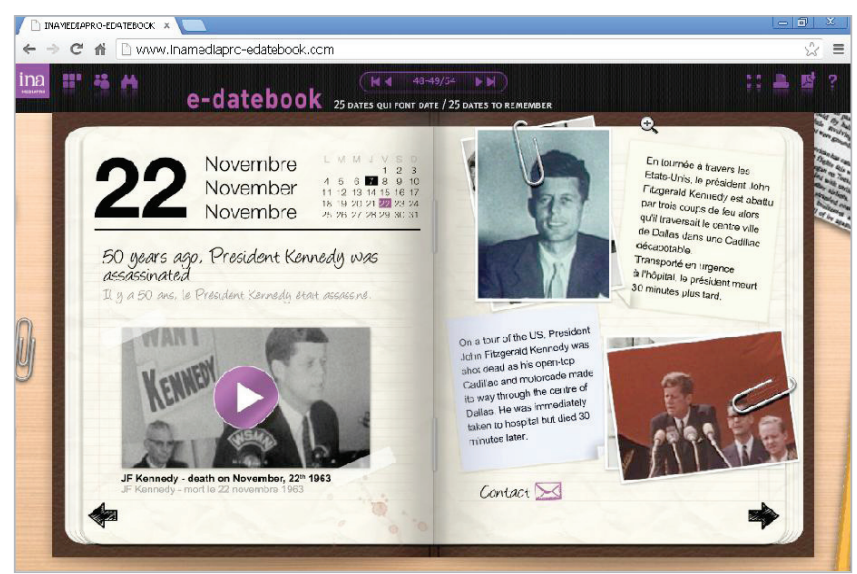

Figura 4. Agenda de InaMédiaPro

http://www.inamediapro-edatebook.com 

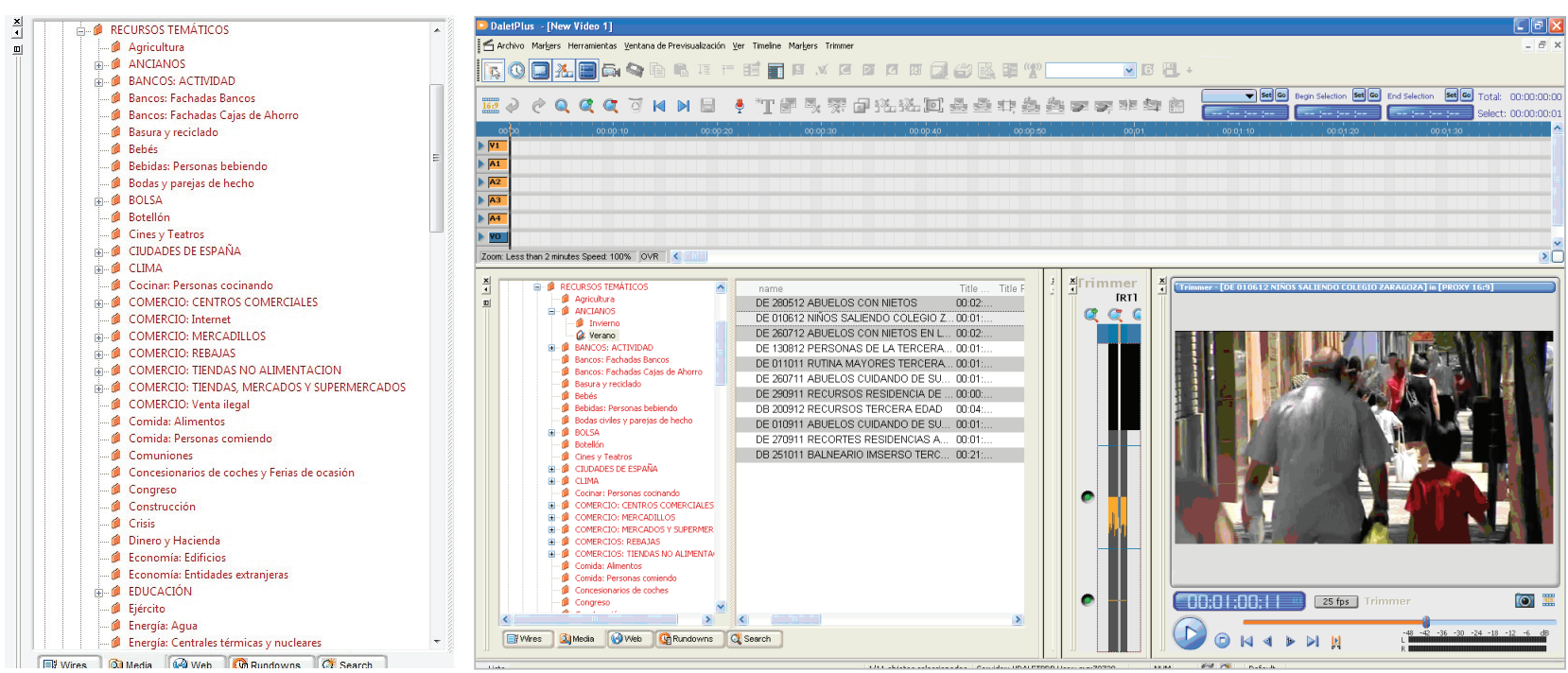

Figura 5. Librería de recursos de Antena $3 T V$

\section{Fichas de organismos}

Información tanto escrita como audiovisual sobre organismos nacionales e internacionales (principales hitos y personajes con ellos relacionados), que pueden ser susceptibles de convertirse en noticia o completar otras noticias en las que intervienen. Sólo dos cadenas, BTV y TVC, realizan en la actualidad este producto.

Los periodistas llevan a cabo la selección del material original en 8 de las 10 televisiones estudiadas

\section{Fichas de países}

Información escrita sobre historia, economía, política, sociología, principales personajes, etc. del país, y material audiovisual para ilustrarlo. Ninguna de las televisiones encuestadas realiza este producto.

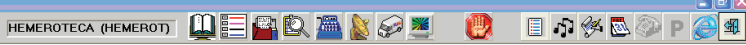

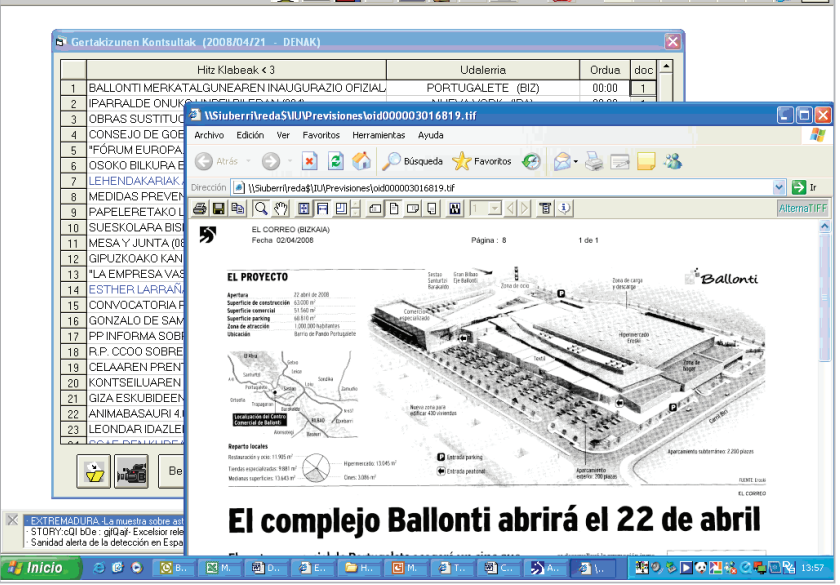

Figura 6. Previsiones de EITB

\section{Guías de recursos en internet}

Selección de recursos clasificados por temáticas (las de mayor interés para la cadena), webs de los principales organismos y medios de comunicación tanto nacionales como internacionales, $y$, en general, recursos fiables, sobre todo aquello que pudiera resultar de interés para los usuarios. De las televisiones encuestadas sólo las realizan dos: BTV y TVC.

\section{Librerías de recursos}

Se trata de poner online, a disposición de los redactores, un amplio abanico de las imágenes de recurso más habitualmente empleadas, para evitarles realizar búsquedas de última hora y eludir los colapsos que ocurren en los sistemas digitales en momentos puntuales. Este producto es realizado por dos cadenas: Antena 3 TV y TVC. En Antena 3 TV (figura 5) la librería de recursos se ubica en el sistema de edición y

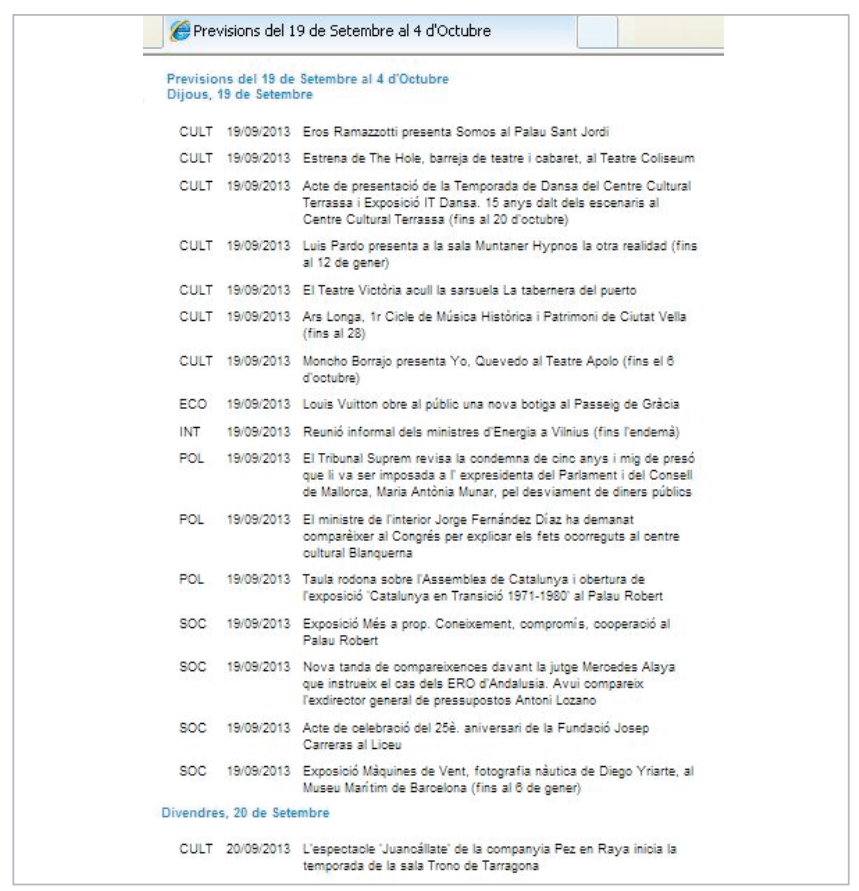

Figura 7. Previsiones de TVC 


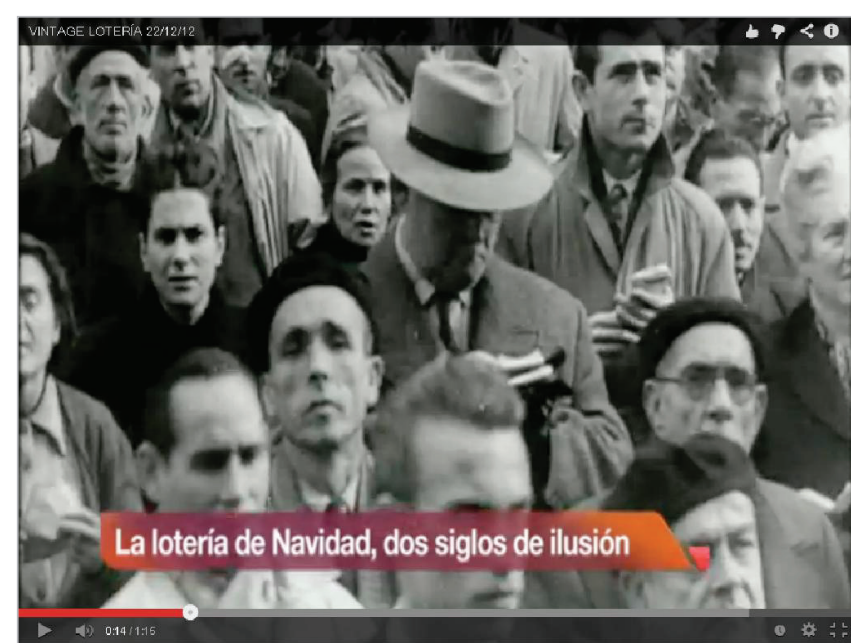

Figura 8. Reportajes Vintage de TVE

está organizada en subcarpetas temáticas por las que los redactores pueden navegar y acceder al material en el mismo momento del montaje de sus piezas. No incluye información escrita (personajes, localización, etc.), a excepción de la fecha, que aparece en el título de los clips.

\section{Previsiones}

Agenda de acontecimientos que se prevé que ocurran. Incluyen información sobre los antecedentes del hecho e imágenes relacionadas con él. Solamente dos cadenas entre las encuestadas las realizan: EITB (figura 6) y TVC (figura 7), ambas exclusivamente con información escrita.

Es muy bajo el porcentaje de productos documentales realizados por los centros de documentación directamente para su emisión o para la web

\section{Productos de recuperación del archivo}

Se trata de dar a conocer el material del archivo. Puede tener dos tipos de usuarios. El primero y más inmediato, el redactor, que utiliza el material para elaborar sus piezas, y el segundo, el espectador, que puede consumirlo directamente, bien porque se emite o se publica en la web. Estos productos pueden adoptar las formas siguientes:

- Selección de materiales de archivo para uso de los redactores.

- Realización de piezas con material de archivo para su emisión. Algunos ejemplos en televisiones que no aparecen en nuestra muestra de análisis, son la serie de microespacios de TVE titulados Vintage, que se emitieron a finales de 2012 y principios de 2013, en los que el centro de documentación ofrecía el producto editado con locución ${ }^{5}$ (figura 8); o los editados del programa Imágenes del siglo $X X$, sólo con música y con texto postproducido (rótulos) de $C N N^{6}$ (figura 9).

- Difusión en la web de piezas ya emitidas sobre acontecimientos históricos o de aquellas que sin serlo, recuperan

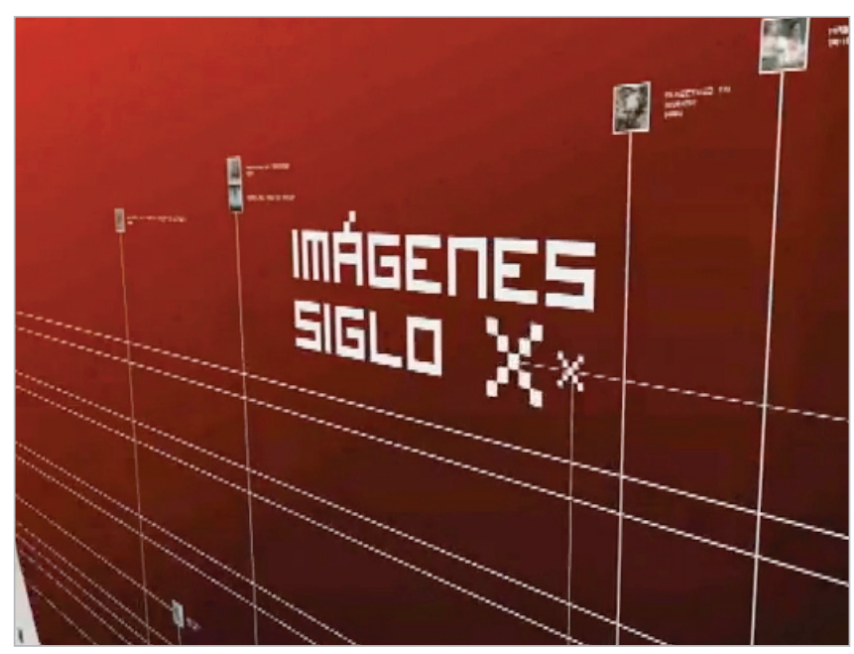

Figura 9. Reportajes Imágenes del siglo XX de CNN Ejemplo: http://youtu.be/jWk6TAoFA9c

su vigencia de manera puntual. Tres cadenas de la muestra (CRTVG, RTVV y TVC) realizan productos de este tipo. Destaca el proyecto de archivo online del centro de documentación de CRTVG: Pasouoquepasou' (Pasó lo que pasó) que intenta poner a disposición del público el archivo de la televisión gallega para mostrar lo que ha pasado en Galicia desde 1985, fecha en la que la CRTVG comenzó a emitir (figura 10). De momento, el proyecto cuenta con unos 400 vídeos (piezas cortas o resúmenes del material del archivo) online, que planean seguir incrementando en tandas de 50 videos al mes. El Departamento de Documentación de Canal Sur también ofrece un servicio parecido a través de Memoranda, un blog desde el que pretende difundir el archivo audiovisual del grupo RTVA .

\section{Resúmenes del año}

Relación cronológica de los principales hechos acaecidos en el año, agrupados por áreas temáticas (economía, política, sanidad, sociedad, cultura, deportes, sucesos, internacional), y/o por tipos de acontecimientos (personajes, noticias

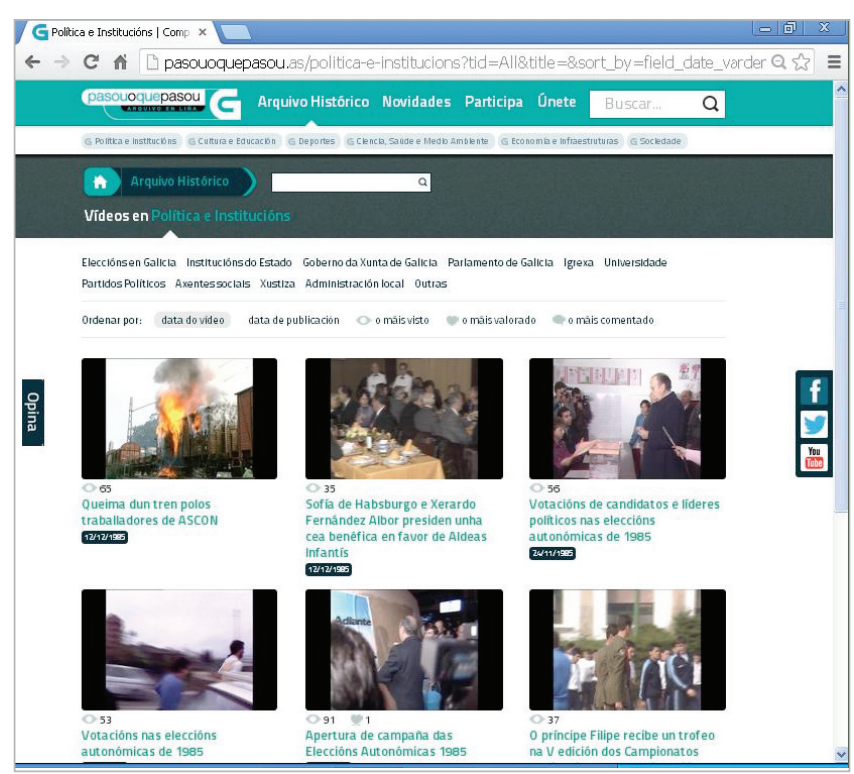

Figura 10. Archivo online de CRTVG: Pasouoquepasou http://pasouoquepasou.crtvg.es 


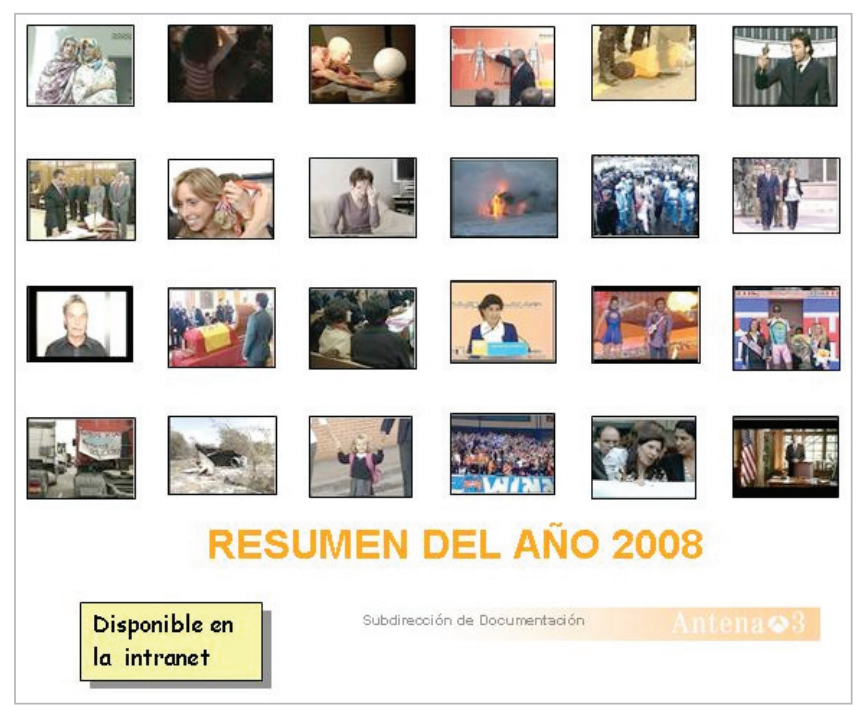

Figura 11. Resumen del año de Antena 3 TV

significativas, necrológicas, curiosidades, prensa rosa, etc.). Ofrecen información sobre la noticia y el material audiovisual más relevante. De las televisiones encuestadas, cuatro realizan este producto: Antena 3 TV (figura 11), EITB (figura 12), Telecinco y TVC. Como en los casos anteriores incluyen uno u otro tipo de información, pero no las dos.

La formación de usuarios impartida por los centros de documentación se limita básicamente a las bases de datos propias

\section{Discusión y conclusiones}

Este artículo presenta una descripción del estado actual de las tareas documentales y de los centros de documentación en las televisiones de España, así como por primera vez en la bibliografía especializada, un mapa de la implantación de productos documentales en dichos centros. Aún con la limitación que representa la ausencia de datos de dos cadenas españolas de relevancia, como son TVE y Canal sur, el análisis de los datos ofrecidos por las 10 televisiones que han participado en la muestra permite presentar algunas conclusiones sobre la situación de la documentación audiovisual en televisión en nuestro país.

\section{Proceso de cambio}

A nivel global se aprecia que los centros de documentación de televisión se encuentran inmersos en un proceso de cambio del que hasta ahora los aspectos más visibles son la reducción de las plantillas y la realización por parte de periodistas de labores tradicionalmente desempeñadas por documentalistas.

\section{Tareas documentales realizadas por periodistas}

Los datos recogidos sobre la participación de los periodistas en tareas documentales, son muy elocuentes. En todos los centros estudiados, los redactores buscan la información escrita y audiovisual en internet y en 7 de ellos también la

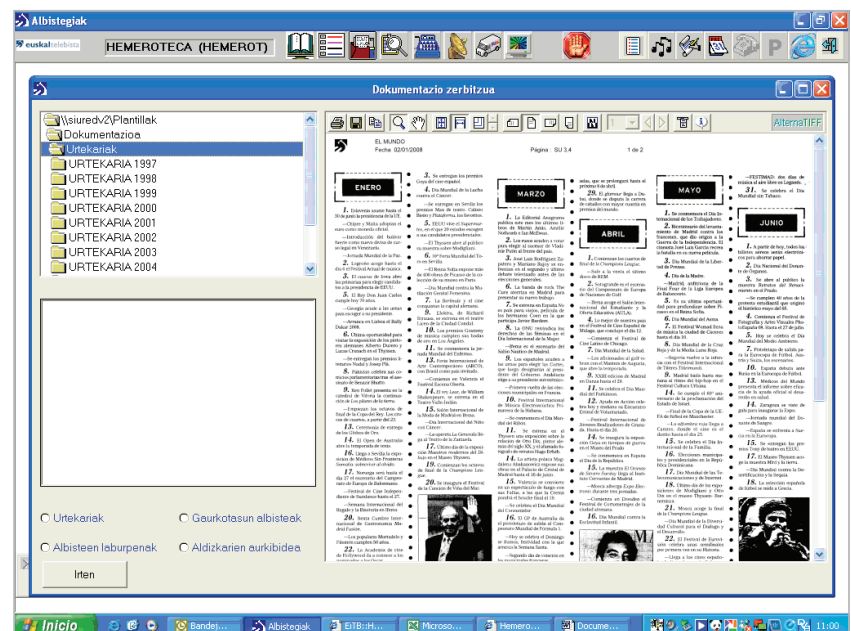

Figura 12. Anuarios de EITB

audiovisual en el archivo de la cadena. Sin embargo, sólo en 3 centros utilizan las bases propias de prensa, quizá porque para buscar en ellas se requiere una formación previa. Más preocupante es que en 8 de los 10 centros la selección del material original recaiga de alguna manera en los redactores. La selección definitiva por parte de los periodistas tiene consecuencias negativas para la cadena, ya que se trata de una operación no normalizada, en la que selecciona en función de sus criterios personales, sin tener en cuenta las necesidades del archivo (Giménez-Rayo, 2007, p. 106). No obstante, la selección de carácter orientativo presenta aspectos positivos, como son implicar a los usuarios en la creación del archivo y dar a conocer la labor del centro de documentación (Giménez-Rayo, 2012, p. 83).

\section{Tareas documentales en los centros de documentación}

La mayoría de los centros de documentación encuestados continúan realizando las labores documentales habituales (análisis de la emisión y del material original, selección del material original y recuperación de la información escrita y audiovisual), a pesar de que ahora también los redactores realicen algunas de ellas. La labor más afectada, hasta el momento, es la búsqueda de información escrita.

\section{Formación de usuarios}

A pesar de las posibles expectativas existentes sobre el alcance de esta función, la realidad es que la formación impartida por los centros de documentación se limita básicamente a las bases de datos propias y a las herramientas y aplicaciones relacionadas con documentación, y en muy pocos centros las extienden a la búsqueda de información en general, en todo tipo de fuentes. Ahora buscar es muy fácil, pero encontrar la información adecuada es más difícil. Hay que saber qué y para qué se busca, y, por supuesto, dónde buscarlo. Con los cursos los redactores aprenderían a buscar tanto en internet como en las bases de datos de las cadenas el material más adecuado a sus necesidades, a organizarlo, y, sobre todo, a evaluar la información desde la fiabilidad y no desde el deseo de ser el primero en ofrecer la noticia, lo que ya ha llevado en más de una ocasión a emitir materiales erróneos ${ }^{9}$.

El principal inconveniente que presenta esta formación es lo difícil que resulta convencer a la empresa de su rentabilidad. 


\section{Productos documentales}

La mayoría de los productos documentales de las televisiones son herederos de la prensa escrita. Es todavía muy bajo el porcentaje de productos que combinan información escrita y audiovisual, por lo que a pesar de que suelen tener buena acogida entre los usuarios, sólo satisfacen en parte las necesidades de los redactores, o en cuanto a información textual o en lo que a la audiovisual se refiere, pero no aúnan ambas. Esto último permitiría a nuestro juicio ahorrar al periodista tiempo y trabajo, ya que en un mismo producto tendría acceso a los dos tipos de material.

Los productos documentales se crean para uso interno de la redacción y no para la audiencia, con la excepción clara de CRTVG

La mayoría de las cadenas encuestadas utilizan los medios internos (correo electrónico, intranet) para difundir estos productos. Aunque lo más efectivo sería incluirlos en los sistemas de edición, muchas cadenas los siguen presentando en la intranet o simplemente los envían por correo electrónico.

Es significativa la bajísima existencia de productos documentales realizados por los centros de documentación directamente para su emisión o para la web. El valioso proyecto de CRTVG y las experiencias aisladas de otras cadenas que no han participado en nuestro estudio y que ya han sido señaladas, son un pobre balance. Este estudio evidencia que los documentalistas de televisión en España no han dado el salto a la creación de materiales directamente para la audiencia, como han hecho sus colegas de la prensa escrita de $L a$ vanguardia, $A B C$, El mundo deportivo, El país, etc. (Guallar, 2011a, 2011b, 2013; Rubio-Lacoba, 2007), en una situación, por lo que parece, más similar a la de los documentalistas de radio (con la excepción de los productos documentales que realiza el servicio de documentación de la Cadena Ser). A falta de estudios comparativos entre medios, una posible explicación de esta diferencia entre televisión y prensa se podría buscar en la mayor dificultad o especialización de la edición de documentos audiovisuales frente a los textuales. La escasa repercusión de los productos documentales televisivos en el usuario final conduce con toda probabilidad a que sean más visibles sus inconvenientes, y en cambio, no se lleguen a apreciar plenamente sus ventajas.

Entre los primeros, el hecho de que estén realizados en general para ayuda de los redactores y en menor medida para consumo directo de los telespectadores o usuarios de las webs, hace que resulte difícil demostrar su rentabilidad, ya que son caros, principalmente por el elevado coste en tiempo que requiere, no sólo su elaboración, sino sobre todo su actualización. Hay que tener en cuenta que mantener al día este tipo de materiales implica mucho trabajo, ya que deben actualizarse de una manera periódica, pues de nada sirve realizar un producto si para cuando se necesita está anticuado. De ahí que algunos centros aleguen no poder destinar personal a su realización porque ello supondría dejar de realizar tareas que son más necesarias en el día a día.
Vale la pena enfatizar algunas de las ventajas. En primer lugar, la potenciación del archivo, lo que a medio y largo plazo puede redundar en beneficios económicos. En segundo lugar, y en un plano general, pueden incidir positivamente en la imagen y el prestigio de la cadena. Por último, y en un plano estrictamente laboral y profesional, favorecen la visibilidad del colectivo de documentalistas, así como su evolución y desarrollo profesional, al permitir potenciar su creatividad y asumir roles más protagonistas y menos subordinados a los periodistas.

\section{Futuros trabajos}

Creemos que es preciso continuar realizando periódicamente estudios de conjunto en la línea del actual, para conocer con precisión la evolución de las tareas documentales en televisión, de los centros de documentación y de su colectivo profesional. Asimismo se considera especialmente necesario profundizar más en la investigación que aquí tan solo se ha iniciado sobre la elaboración de productos documentales en televisión (implantación en los centros, tipo, características, sistema de elaboración, ventajas e inconvenientes), y también -como se ha apuntado antes- realizar estudios comparativos sobre la elaboración de productos documentales en medios de prensa, radio y televisión.

Hay pocos productos documentales que combinan información escrita y audiovisual

\section{Notas}

1. Los autores agradecen la colaboración de los profesionales de documentación que han respondido los cuestionarios y han facilitado ejemplos e imágenes de los productos documentales de sus centros: Eugenio López-De-Quintana (Antena 3 TV), Virginia Martínez (BTV), María-Jesús López (CRTVG), Luis Isusi y Jesús Andérez (EITB), Daniel GarcíaHernández (La sexta), Marcela Pastor (RTPA), Lola Alfonso (RTVV), Francisco-Javier Solano (Telecinco), Blasi Naranjo (Telemadrid) e Imma Rull y Alícia Conesa (TVC).

2. En aras de una mayor claridad expositiva, en las tablas 1 y 5 la ordenación de las cadenas de televisión no sigue el orden alfabético habitual en las demás tablas.

3. EITB no trata el material original. El único material original que se conserva en el archivo son las selecciones que envían los redactores.

\section{4. http://www.inamediapro-edatebook.com}

El INA tiene una sección de efemérides en: http://www.inamediapro.com/pages_actus/ephemeride.htm/

5. El 22 de diciembre de 2012 en el Canal 24 Horas de TVE se emitió por primera vez una pieza realizada totalmente por Documentación con material de archivo sobre la lotería de Navidad.

http://youtu.be/7tTF4IPVK4M

6. Por ejemplo, reportaje con imágenes de películas de MarIon Brando:

http://youtu.be/jWk6TAoFA9c

7. http://pasouoquepasou.crtvg.es 


\section{8. http://blogs.canalsur.es/documentacionyarchivo}

9. Algunos ejemplos: imágenes del hundimiento del Pacific Sun en Nueva Zelanda en 2008 como si fueran las del crucero Costa Concordia en 2011 (Martín, 2012); una tormenta en el festival Heineken de Venecia en 2007 como las primeras imágenes del terremoto de Haití en 2010; una riada en 2008 en Maine, EUA, afirmando que eran de Ciudad Real en 2010 (El país, 2010).

Este trabajo ha contado con el apoyo de Agaur (Grupo de investigación consolidado "Cultura y contenidos digitales" 2009-SGR-177) y forma parte del proyecto financiado por el Ministerio de Economía y Competitividad, Ref: CSO201239518-C04-01.

\section{Bibliografía}

Agirreazaldegi-Berriozabal, Teresa (2007). "Claves y retos de la documentación digital en televisión". El profesional de la información, v. 16, n. 5, pp. 433-442.

http://elprofesionaldelainformacion.com/contenidos/2007/ septiembre/05.pdf

http://dx.doi.org/10.3145/epi.2007.sep.05

Aguilar-Gutiérrez, Manuel; López-De-Solís, Iris (2010). "Nuevos modos de trabajo de una redacción digital integrada: el caso de los servicios informativos de TVE". El profesional de la información, v. 19, n. 4, pp. 395-403. http://dx.doi.org/10.3145/epi.2010.jul.09

Alfonso-Noguerón, Lola (2009). “De la videoteca al robot pasando por Tarsys. Nuevos sistemas de gestión multimedia en Radiotelevisión Valenciana". El profesional de la información, v. 18, n. 3, pp. 333-340.

http://elprofesionaldelainformacion.com/contenidos/2009/ mayo/12.pdf

http://dx.doi.org/10.3145/epi.2009.may.12

Caldera-Serrano, Jorge; Arranz-Escacha, Pilar (2012). Documentación audiovisual en televisión. Barcelona: Editorial UOC. Colección El profesional de la información, n. 13. ISBN: 9788490299821

Caridad-Sebastián, Mercedes; Hernández-Pérez, Tony; Rodríguez-Mateos, David; Pérez-Lorenzo, Belén (2011). Documentación audiovisual: nuevas tendencias en el entorno digital. Madrid: Síntesis. ISBN: 9788497567466

Conesa-Santamaría, Alícia (2012). “De la videoteca a l'arxiu digital: evolució del Departament de Documentació de Televisió de Catalunya". Trípodos, n. 31, pp. 99-108.

http://www.tripodos.com/index.php/Facultat Comunicacio_Blanquerna/article/view/40

De-Bustos-Pérez-De-Salcedo, Pilar (2007). "Sistemas integrados y gestión documental. La experiencia en Telecinco". El profesional de la información, v. 16, n. 5, pp. 450-455. http://elprofesionaldelainformacion.com/contenidos/2007/ septiembre/07.pdf

http://dx.doi.org/10.3145/epi.2007.sep.07

El país (2010). “TVE emite imágenes falsas del terremoto en Haiti". Elpais.es, 14 enero

http://sociedad.elpais.com/sociedad/2010/01/14/ actualidad/1263423611_850215.html
Estrada-Nora-González, Belén; Patallo-Fernández, Cristina; Pastor-Blanco, Marcela (2009). "Servicio de documentación de la Televisión del Principado de Asturias (TPA)". El profesional de la información, v. 18, n. 3, pp. 326-332.

http://elprofesionaldelainformacion.com/contenidos/2009/ mayo/11.pdf

http://dx.doi.org/10.3145/epi.2009.may.11

Giménez-Rayo, Mabel (2007). Documentación audiovisual de televisión: la selección del material. Gijón: Trea. ISBN: 9788497043205

Giménez-Rayo, Mabel (2012). “La documentación audiovisual en televisión en el mundo 2.0: retos y oportunidades". Trípodos, n. 31, pp. 79-97.

http://www.tripodos.com/index.php/Facultat_ Comunicacio_Blanquerna/article/view/39/24

Guallar, Javier (2011a). “Documentación y periodismo digital. Repertorio de productos documentales y ejemplos de buenas prácticas". IX Coloquio intl de ciencias de la documentación: La documentación en los medios de comunicación. Universidad de Salamanca, 7-8 abril.

http://eprints.rclis.org/15555

Guallar, Javier (2011b). "La documentación en la prensa digital. Nuevas tendencias y perspectivas". III Congreso intl de ciberperiodismo y web 2.0, Bilbao, Universidad del País Vasco, 9-11 noviembre, pp. 52-68. http://eprints.rclis.org/16326

Guallar, Javier (2013). “Documentación en la prensa digital. Hemerotecas digitales y productos documentales". IV Congreso de investigación interdisciplinar en comunicación, información y documentación, Universidad de Zaragoza, Zaragoza, 3 julio. http://eprints.rclis.org/19933

Guallar, Javier; Abadal, Ernest; Codina, Lluís (2012). “Hemerotecas de prensa digital. Evolución y tendencias". El profesional de la información, v. 21, n. 6, pp. 595-60.

http://eprints.rclis.org/18199

http://dx.doi.org/10.3145/epi.2012.nov.06

Hidalgo-Goyanes, Paloma (2005). "La documentación audiovisual de las televisiones. La problemática actual y el reto de la digitalización". Documentación de las ciencias de la información, v. 28, pp. 159-171.

http://revistas.ucm.es/index.php/DCIN/article/viewFile/ DCIN0505110159A/19216

López-de-Quintana-Sáenz, Eugenio (2007). “Transición y tendencias de la documentación en televisión: digitalización y nuevo mercado audiovisual". El profesional de la información, v. 16, n. 5, pp. 397-408.

http:/elprofesionaldelainformacion.com/contenidos/2007/ septiembre/01.pdf

http://dx.doi.org/10.3145/epi.2007.sep.01

López-de-Quintana-Sáenz, Eugenio (2008). “De la intermediación a la anticipación: rutas alternativas en la documentación de la producción audiovisual". X Jornadas de gestión de la información, Madrid, 20-21 noviembre, pp. 11-22. http://eprints.rclis.org/12538

Martín, Carlos (2012). “En caso de duda consulte a su docu- 
mentalista". Enredan-doc, 23 noviembre. http://enredandoc.wordpress.com/2012/11/23

Rubio-Lacoba, María (2007). Documentación informativa en el periodismo digital. Madrid: Síntesis. ISBN: 978849756 4595
Rubio-Lacoba, María (2011). "Documentalistas y periodistas en cibermedios". III Congreso intl de ciberperiodismo y web 2.0: La transformación del espacio mediático, Universidad del País Vasco, 9-11 noviembre, pp. 103-118. http://eprints.rclis.org/16328

\section{Colección de libros de bolsillo}

\section{El profesional de la información (Editorial UOC)}
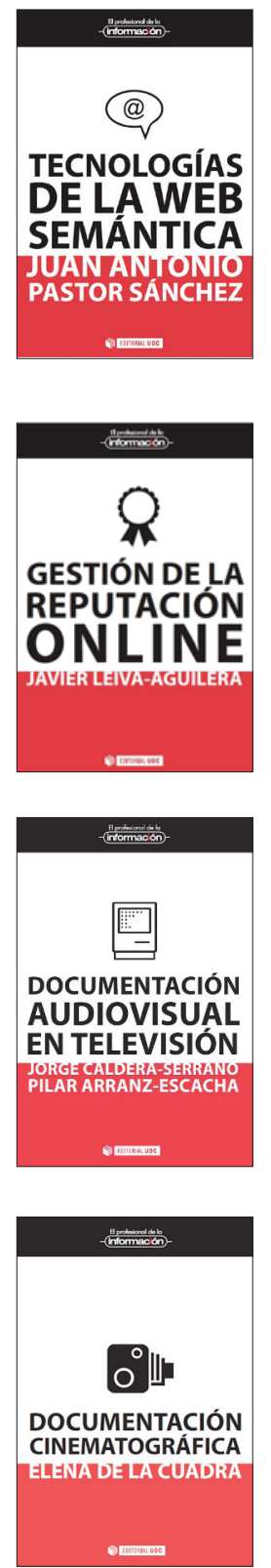
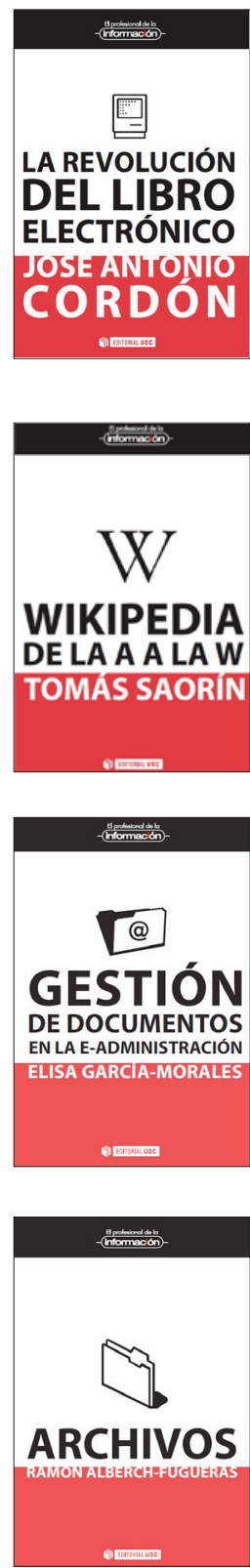
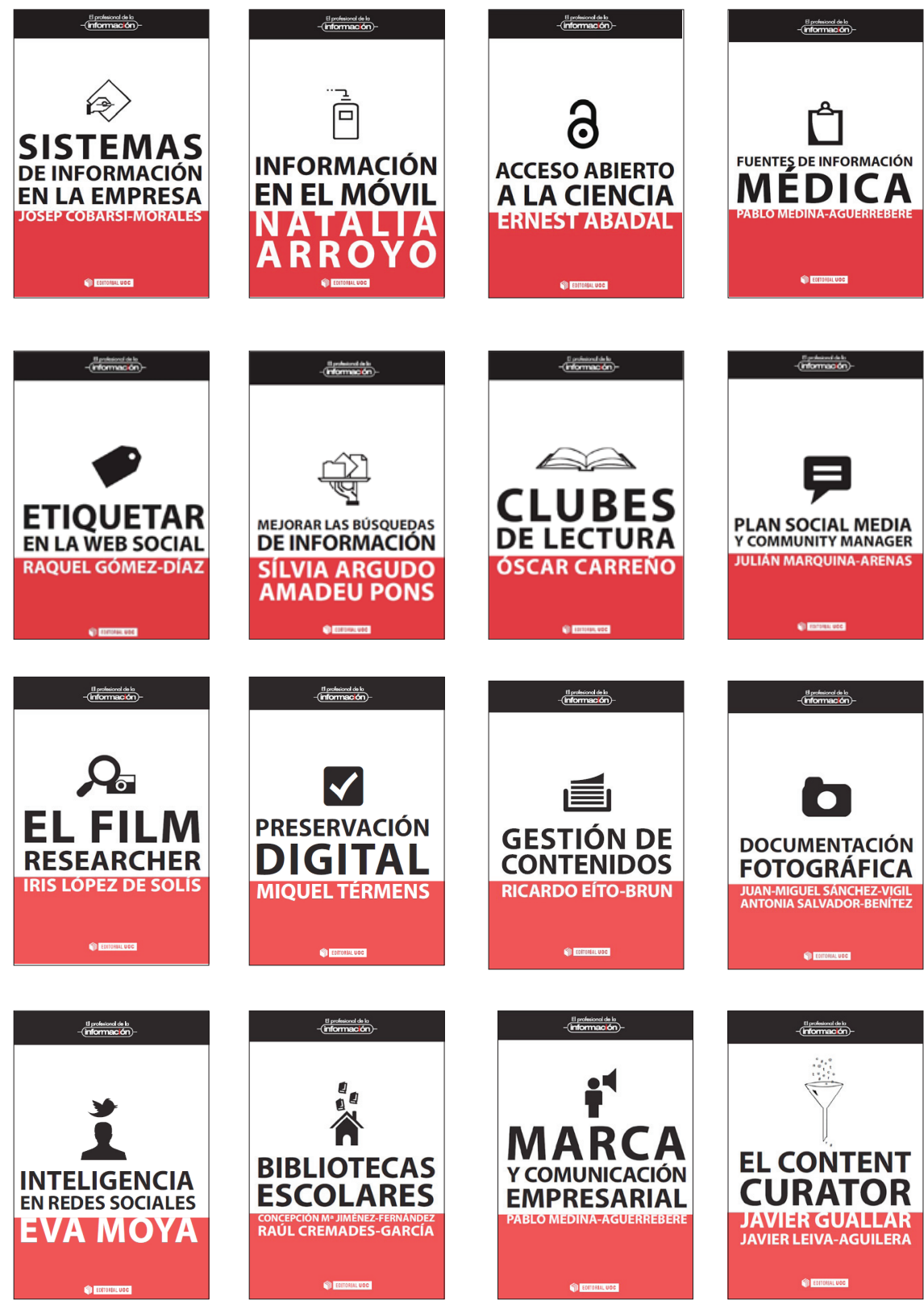
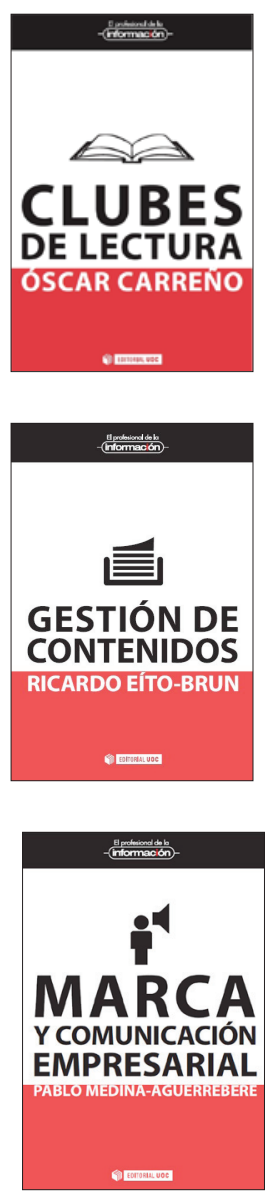
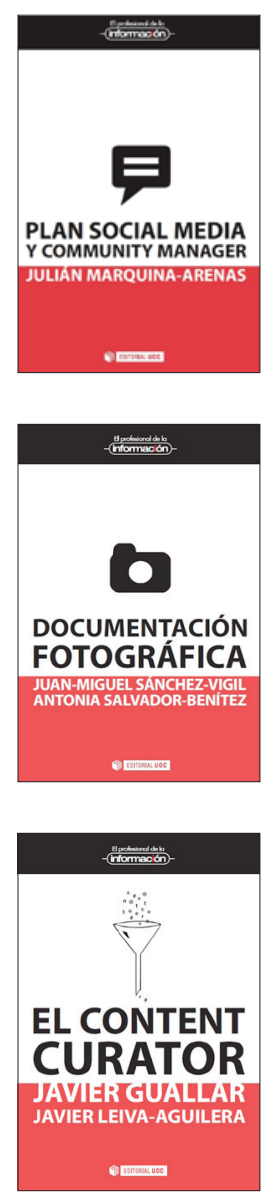

Más información: http://www.elprofesionaldelainformacion.com/libros.html 